\title{
A PROPÓSITO DE UN CONJUNTO DE CAPILLAS ABIERTAS
}

\section{José Guadalupe Victoria}

La histor iografía acerca de la arquitectura novohispana del siglo xvI puede decirse que ha proporcionado una visión de conjunto de dicha expresión plástica. Sin embargo, a mi modo de ver, ha reparado poco en las transformaciones padecidas por muchos monumentos a lo largo de la época colonial y, más todavía, durante el siglo pasado y lo que va del presente. La mayoría de los autores han advertido algunas de esas transformaciones, pero pocos las han precisado. Por consiguiente, esos edificios - considerados de manera aislada o en conjunto-, constituyen verdaderos problemas para los estudiosos del patrimonio artístico-novohispano.

Apunto lo anterior porque justamente uno de esos problemas vienen a constituirlo numerosas capillas abiertas que, transformadas durante los siglos XVII y XVIII, varios autores no las incluyeron en sus estudios; me refiero particularmente al libro de John Mc Andrew. ${ }^{1}$

En las siguientes líneas me propongo estudiar cuatro capillas abiertas; sin que, en modo alguno, sea yo el primero en referirme a ellas. Dichas capillas son: la de Santa Catarina (Coyoacán) y la de San Sebastián Chimalistac (San Ángel), ambas en el Distrito Federal; así como las de San Miguel Anenecuilco y Santa María Temimilcingo. Estas dos en el Estado de Morelos.

Como señalé atrás, ninguna de ellas ha sido consignada en las obras que estudian la capillas abiertas de manera especial, sin embargo, existen pequeñas monografías acerca de dos de ellas; el conjunto conventual de Temimilcingo Morelos fue estudiado -aunque de modo sucinto- por Luis Fernando Lozano ${ }^{2}$ y la iglesia de Chimalistac llamó la atención de Elena Zea. ${ }^{3}$ Respecto a los otros conjuntos, poco es lo que se ha escrito, como no sean las menciones que aparecen en obras generales.

1 John Mc Andrew, The Open-Air churches of the Sixteenth-Century Mexico: Cambridge, Mass., Harvard University Press, 1965.

2 Luis Fernando Lozano, "El convento y la capilla abierta de Temimilcingo." Boletin del Instituto Nacional de Antropologia e Historia, núm. 27, marzo de 1967.

3 Elena Zea Prado. La iglesia de San Sebastian Chimalistac en Coyoacán. México, UNAM, Facultad de Filosofía y Letras, 1976, tesina. Lic en Mistoria. 
Para comprender mejor las transformaciones de que han sido objeto, etudiaré cada capilla por separado.

\section{Temimilcingo}

El primero en percatarse de que originalmente esta capilla era abierta, fue Luis Fernando Lozano. Según él "posteriormente convertida en capilla cerrada, al arreglarle una segunda nave, perpendicular al eje de la primitiva capilla, y lateral a la nave de la misma". 4 Continúa este autor en descripción -que por cierto resulta poco clara- y concluye, apoyándose en el parecer de John $\mathrm{Mc}_{\mathrm{c}}$ Andrew que:

La capilla de Temimilcingo perteneció a uno de los dos tipos fundamentales de capillas abiertas, desarrollados a partir de 1540, que menciona Mc Andrew: el de la capilla con pórtico, que, en el caso que nos ocupa estaba formado por los tres arcos de la nave original, construida perpendicularmente al eje del presbiterio. ${ }^{5}$

En cuanto al funcionamiento de la mencionada capilla, dicho autor alude a las reflexiones del propio Mc Andrew, sobre el mismo tópico, y apunta:

Una vez que la iglesia conventual estaba concluida, o en vías de serlo... la primitiva capilla abierta, de carácter provisional, era a menudo reemplazada por otra más estable, o bien, si las condiciones de la capilla original lo permitían, se conservaba ésta como capilla de indios después de construida la iglesia conventual. No ha de haber ocurrido esto en Temimilcingo, puesto que todo parece indicar que la primitiva capilla abierta continuó funcionando, terminada ya la edificación del convento, y que, en lugar de construir una iglesia conventual, hizo las veces de ésta la primitiva capilla con pórtico, a la que se añadió una segunda nave, y posteriormente la torre, para transformarla en capilla cerrada, que es la que aún contemplamos. ${ }^{6}$

Otras consideraciones que hace el autor sobre el monumento, así como la conclusión final acerca del mismo, las comentaré posteriormente.

4 Luis Fernando Lozano, op. cit., p. 3.

5 Ibidem, p. 6.

6 Ibidem, p. 67. 


\section{Anenecuilco}

El nombre de este pueblo denota su clara filiación prehispánica. Fue un importante centro ceremonial, como lo muestran las estructuras arquitectónicas descubiertas hace algunos años; la iglesia actual se desplanta sobre una de dichas estructuras.

Cuando visité el lugar por vez primera - hace aproximadamente seis años- la estructura de la iglesia llamó poderosamente mi atención, pues resultaba un tanto atípica. Este parecer lo corroboró una plática que tuve con el doctor Jorge Gurría Lacroix, quien me indicó que desde su punto de vista, la iglesia de Anenecuilco había sido capilla abierta en su origen; además de advertirme el parentesco que muestra con la de Temimilcingo, en el mismo Estado de Morelos.

Efectivamente, el primer elemento que permite suponer que esta capilla fue abierta es su aspecto sumamente alargado; en seguida, el hecho de que su altar mayor está orientado hacia el sur, y el coro sólo ocupa la mitad del ancho de la nave, de acuerdo con la disposición actual de la igelsia. Observando el extremo oriente de la estructura, por el exterior, destacan un par de muros derruidos que están dispuestos en sentido perpendicular al segundo tramo de la iglesia. Sin embargo, lo que definitivamente me lleva a afirmar que se trata de una capilla abierta con los tres arcos cegados en la fachada poniente y, más aún, el gran arco apuntado - hoy tapiadoque originalmente comunicaba la nave de la capilla con el presbiterio de la misma. Se habrá percatado el lector que el presbiterio actualmente está destruido; sólo se conservan los muros laterales que permiten afirmar que existió, así como restos de pintura mural sobre ellos; es probable que haya sido presbiterio cuadrado.

\section{Chimalistac}

Respecto a esta construcción, quiero señalar primeramente el parecer de Elena Zea, en el sentido de que se trata de una capilla abierta muy tardía. Después de hacer la historia parcial de ese lugar, apunta que la capilla de San Sebastián data del siglo xvin o cuando más de fines del siglo anterior.

Según ella: 
Las peculiares y atípicas características de la capilla... me obligan a relacionarla con otras obras de la misma, y a postular la existencia de tardías capillas abiertas en el siglo xvirt, al sur de la ciudad de México, en contra de la vigencia reducida al siglo xvi que suelen dar a esas estructuras los historiadores del arte. ${ }^{7}$

Que originalmente fue una capilla abierta lo prueba el hecho de que en el muro oriente se advierten arcos de medio punto que, no se puede precisar la fecha, fueron tapiados; además, "aunado a lo peculiar de la planta de la iglesia, permite suponer que se trata de una capilla abierta posteriormente modificada..." 8 De acuerdo con unos planos que datan de hacia 1939, Elena Zea apunta que:

La planta de la capilla era muy simple, compuesta por una nave transversal, rectangular en la proporción de tres cuadrados, ligada con un espacio cuadrangular al centro; es decir, la planta afecta la forma de $\mathrm{T}$ invertida, con el pie muy corto hacia el poniente y los brazos apuntando a norte y sur: hacia el oriente la fachada. ${ }^{9}$

Por la anterior -continúa la autora- la sola contemplación de ese espacio deja ver su aparente incongruencia. Si el espacio cuadrado es -y seguramente lo ha sido siempre - el ábside, resulta imposible la visibilidad del altar desde la nave transversal, salvo en la parte del centro. Por eso pensamos que originalmente se trató de una capilla abierta. ${ }^{10}$

Completa su tesis apuntando que:

sin embargo, no hay en toda la iglesia un solo elemento constructivo o decorativo, ni el aparejo, que pueda referirse al siglo xvi. Ninguna de las muy conocidas características de aquellas centurias se registran en Chimalistac. En cambio, el tipo de aparejo, piedra grande irregular, ahogada en mezcla con pequeñas piedras y el tipo de molduras, dentro de su extrema simplicidad, pueden datarse del siglo xvir. ${ }^{11}$

Concluye su punto de vista de la siguiente manera:

7 Elena Zea Prado, op cit., p. 2.

8 Ibidem, p. 16

9 Ibidem, p. 22

10 lbidem, p. 23.

11 Ibidem. 
Lo que postulamos es que la capilla de Chimalistac, que ahora vemos, se construyó a principios del siglo xvir o muy a finales del xvirl, como capilla abierta, y que para fines de esa centuria o muy a principios de la siguiente se cerraría para convertirla en una capilla "normal", hasta donde esto es posible. En ese segundo momento se harían portada y campanario. ${ }^{12}$

De momento no pretendo refutar esta tesis de Elena Zea, pero reparo en ella para que el lector sea consciente que no participo de la misma; concuerdo sí en que se trata de una capilla abierta modificada en fecha posterior.

\section{Santa Catarina}

Según la información verbal que me proporcionó el doctor Jorge Gurría Lacroix, fue el mismo Luis Fernando Lozano quien advirtió que esta capilla también, originalmente, había sido abierta. Hasta donde investigamos ningún otro autor ha escrito acerca de esta particularidad del monumento.

Poco es lo que se sabe sobre ella y el lugar donde se encuentra; suponemos que era barrio de Coyoacán, si no desde la época prehispánica, cuando menos a partir de la Conquista española. Debió, eso sí, congregar buen porcentaje de indios, al grado de llevar a los frailes del convento grande a construir la capilla que -bastante transformada - se conserva hasta la fecha.

A mi modo de ver son dos las trasformaciones fundamentales que se hicieron al monumento: una fue el alargar el presbiterio original, destruyendo el muro testero; la otra consistió en agregar la torre en la esquina sureste.

Con lo anterior quiero dar a entender que la planta de esta capilla era similar a la de Chimalistac; es decir, adoptada la forma de una $T$ pero, quizás en el siglo xvII y debido a las necesidades del culto, se decidió alargar el presbiterio para proporcionar mayor extensión a la nave. Desgraciadamente ésta es una hipótesis cuya comprobación resulta difícil, si nos atenemos solamente a la estructura en sí. 
Como se habrá advertido desde el principio, son varios rasgos los que mantienen en común estas capillas. El primero que quiero destacar es el que se refiere al lugar donde fueron construidas; pienso que todos, desde la época prehispánica, fueron pequeñas poblaciones cuyo número de habitantes, lejos de aumentar, disminuyó considerable durante el siglo Xvi y, en menor grado, en los siglos siguientes. Así, el número de habitantes no justificaba la construcción de grandes conjuntos conventuales que, demás está decirlo, se erigieron en los grandes núcleos de población indígena. En el caso de las capillas morelenses las cabeceras fueron Cuautla y Xiutepec. Otro tanto ocurrió con los ejemplos del Distrito Federal, pues Coyoacán concentraba gran número de habitantes.

Por lo tanto, desde los inicios de la conquista espiritual, mantuvieron una categoría eclesiástica inferior: eran visitas dependientes de los conventos mayores: Cuautla, Xiutepec y Coyoacán. En ese sentido, aunque los frailes tenían la obligación de realizar una visita periódica, para atender las necesidades de la población, la mayoría de las veces sus moradores acudían al poblado mayor para resolver sus asuntos eclesiásticos y civiles.

En consecuencia, los edificios que se construían en esos lugares eran muy modestos, en cuanto a proporciones se refiere. Lo anterior puede comprobarse fácilmente en algunas regiones del país, donde el proceso de transformación y reconstrucción de las estructuras originales ha sido más lento. En otras partes, donde la población aumentó considerablemente, resultó necesario hacer nuevas iglesias que cumplieran las necesidades de los fieles. Sin embargo, tengo para mí que fue más lo que se reconstruyó y adaptó, que la nueva obra en sentido estricto. Cierto que aún no contamos con estadísticas que nos permitan hablar con mayor firmeza al respecto; pero, en los casos que he estudiado, puedó apuntar que la población aumentó ligeramente y por eso se procuró aprovechar las estructuras antiguas, con lo cual perdían su función original que, por otra parte, ya no tenía sentido, toda vez que la conquista espiritual -al menos en teoría- había tocado a su fin.

Quiero decir, con lo anterior, que en ningún momento pienso en la supervivencia tardía de capillas abiertas en la región central de México, especialmente en las cercanías de la capital, tal como 
DOI: http://dx.doi.org/10.22201/iie.18703062e.1979.49.1124

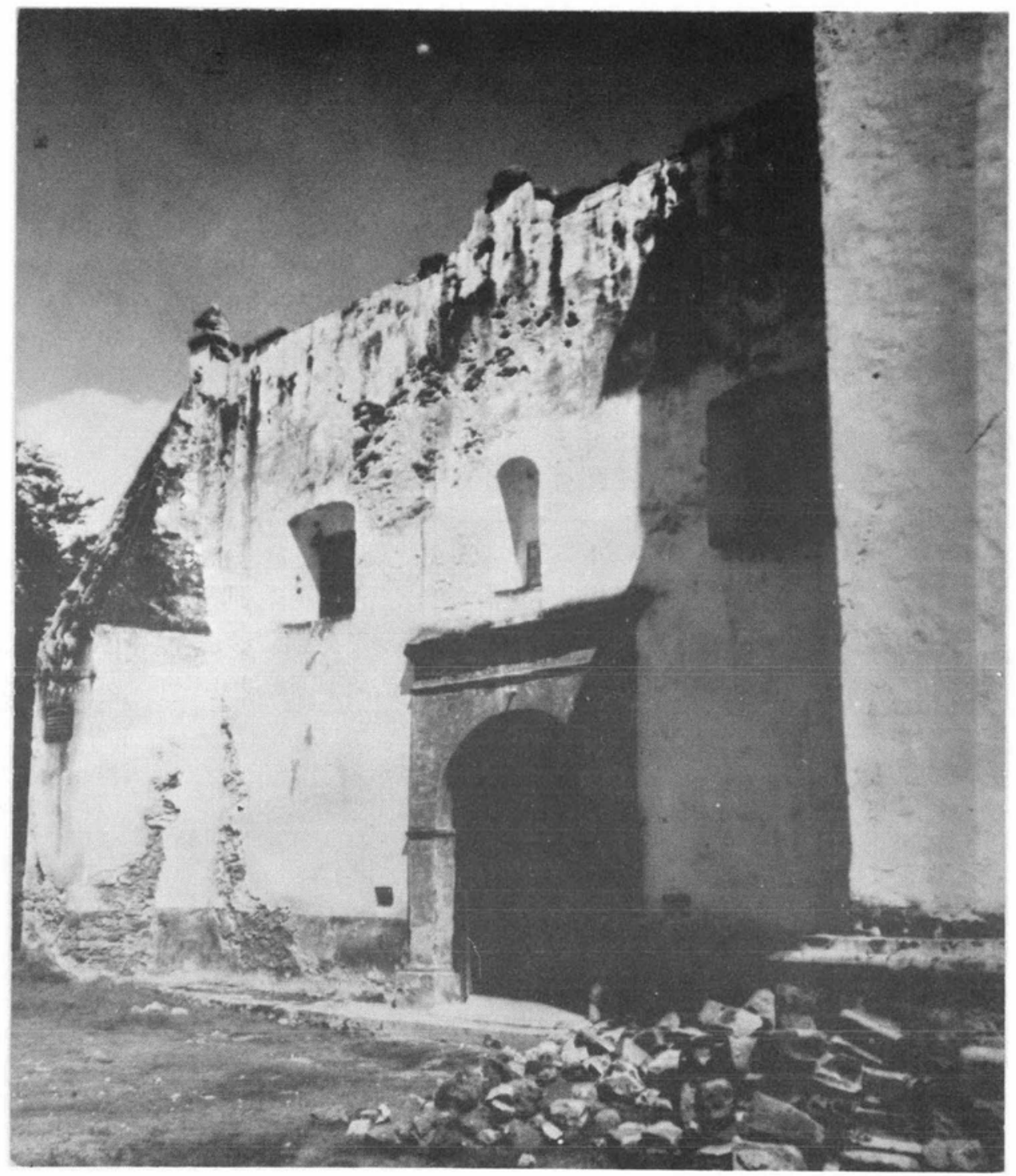

Figura 1. Capilla abierta de Temimilcingo, Mor. 


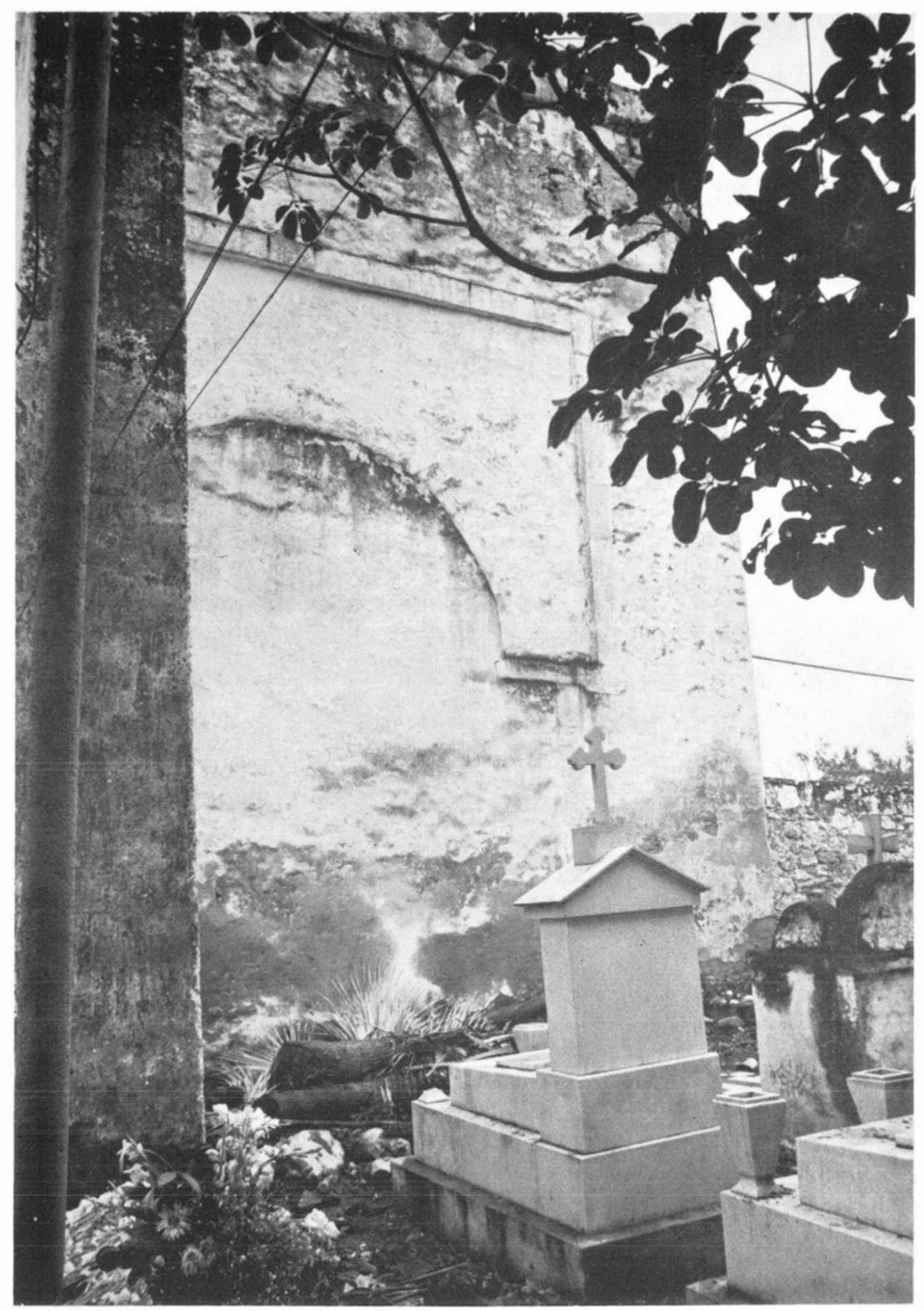

Figura 2. Capilla abierta de Anenecuilco, Mor. 
DOI: http://dx.doi.org/10.22201/iie.18703062e.1979.49.1124

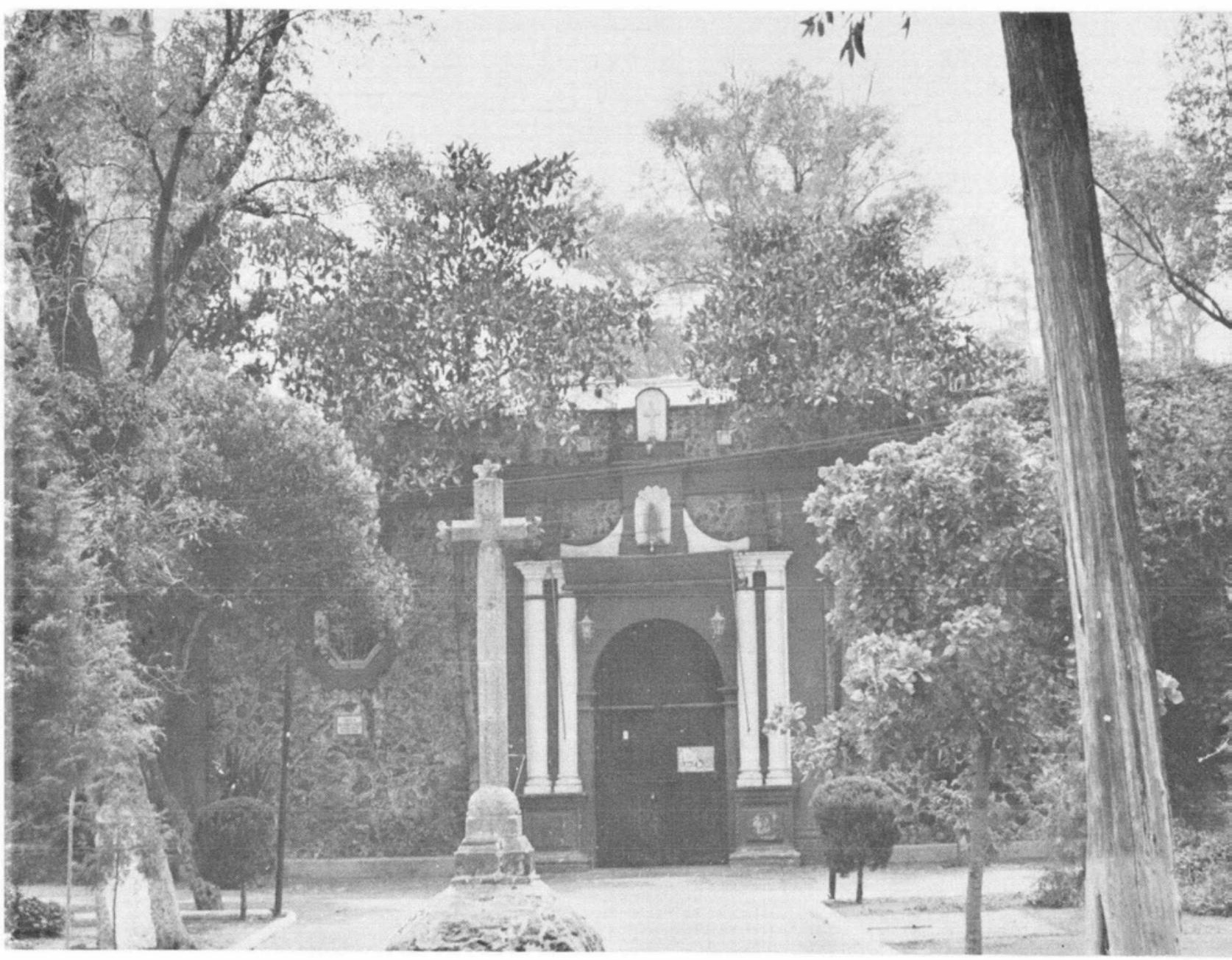

Figura 3. Capilla abierta de Chimalistac, D. F. 
DOI: http://dx.doi.org/10.22201/iie.18703062e.1979.49.1124

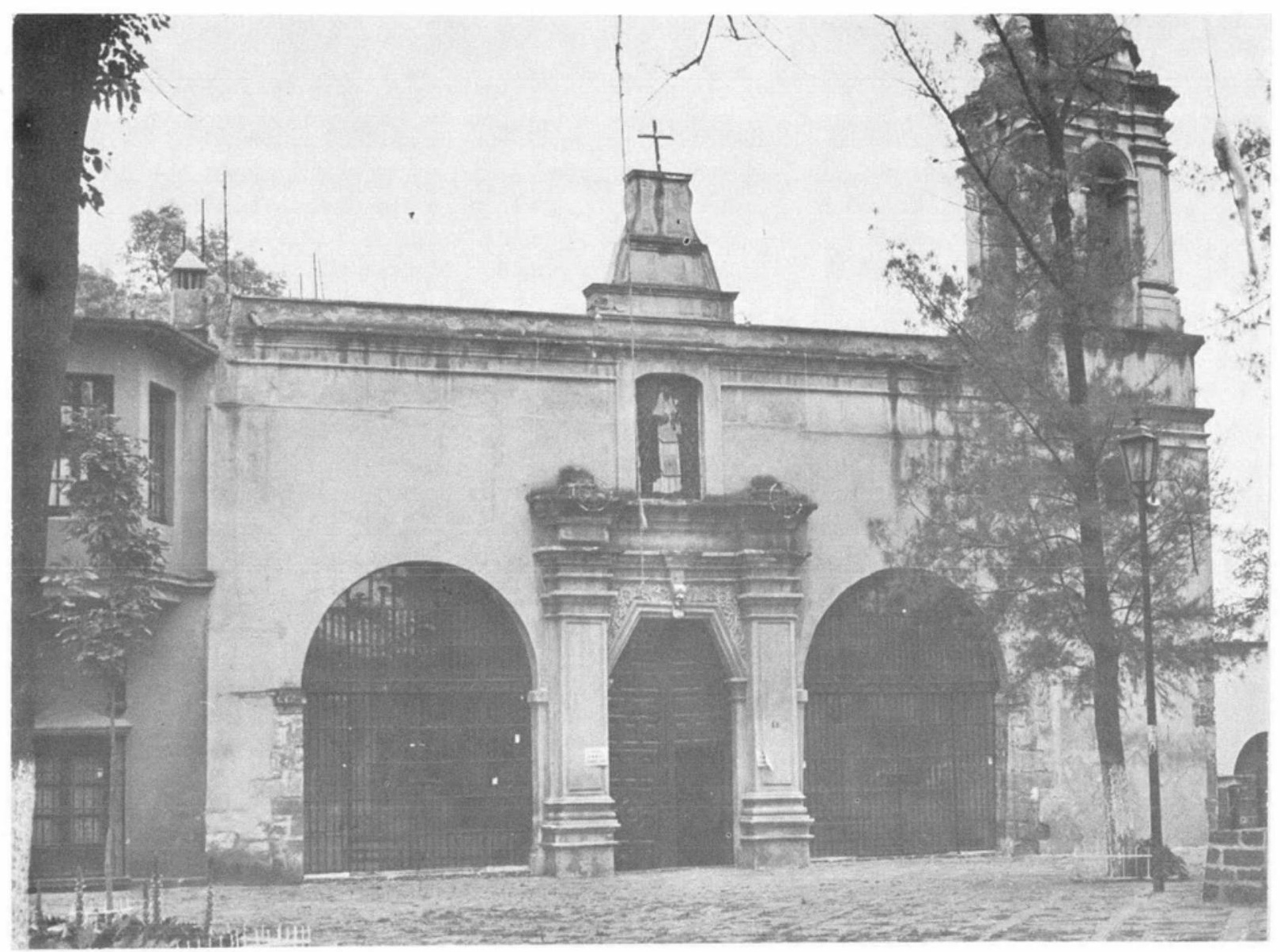

Figura 4. Capilla abierta de Santa Catarina, D. F. 
afirma Elena Zea para el caso de Chimalistac, Santa Catarina y el Barrio del Niño Jesús. Cabe sí, hacer una excepción que no es otra sino el conjunto de fundaciones franciscanas en la Sierra Gorda que datan del siglo xvin, pero cuyas particularidades de evangelización proporcionaron la supervivencia de esas antiguas estructuras. ${ }^{13}$

En lo que se refiere a las estructuras en sí, conviene anotar el gran parecido que guardan en planta y disposición, pues todas pueden integrarse dentro de la clasificación propuesta por Manuel Toussaint; ${ }^{14}$ es decir: adoptan la forma de una $T$ con el pie muy corto, que equivale al presbiterio. En cuanto a su alzado se advierte, en todo los casos, que se prefirió comunicarlas con el exterior por medio de grandes arcos de medio punto; el central de menor tamaño en los ejemplos del Distrito Federal y en'Temimilcingo, Morelos. Menos fácil es advertir el tipo de techumbre que las cubrieron desde un principio. Es probale que originalmente el techo fuera de madera y que, posteriormente, durante el mismo siglo xvi se hayan cubierto con bóvedas. Pienso que cuando se hagan, aunque sean incipientes trabajos de arqueología colonial, estos aspectos se podrán precisar mejor.

Parecen ser varios los posibles ejemplos que sirvieron de inspira. ción a las estructuras aquí estudiadas. En la región tlaxcalteca resul. tan bien significativos los casos de San Esteban Tizatián y San Francisco de la propia ciudad de Tlaxcala; sobre todo esta última, si se toma en cuenta la información proporcionada por Motolinia en el sentido de que para la fiesta de la Pascua del año de 1539 ya estaba acabada la capilla; con lo cual hay que convenir que - por ahoraresulta uno de los ejemplos más tempranos en ese tipo de estructuras.

Sin embargo, es muy probable que el antecedente tan buscado para las capillas que hemos estudiado se encuetre en un lugar más próximo; de ser así propongo lo siguiente: si todas las capillas se construyeron en sitios "dependientes" de un convento mayor, es muy probable que los constructores se inspiraran directamente en el gran conjunto conventual próximo. Obsérvese, por ejemplo, la disposición que guardan la portería y la capilla abierta del convento de

13 Monique Gustín, El barroco en la Sierra Gorda. Misiones franciscanas en el Estado de Querétaro, siglo xviIr, México, Instituto Nacional de Antropología, 1969.

14 Manuel Toussaint, Arte colonial en México. México, UNAM, Instituto de Investigaciones Estéticas, 1962, p. 13. 
Coyoacán, y se advertirá que casi es la misma que mantienen las capillas de Santa Catarina y de Chimalistac. Los edificios morelenses quizá tengan su antecedente en las capillas abiertas de Cuernavaca y Tepoztlán.

Lo que resulta evidente en todos los casos estudiados es la sobriedad con que fueron realizados; pero si recordamos que se localizan en sitios que dependen económicamente de las cabeceras, se cae en la cuenta de que sus habitantes no contaron con recursos económicos para construir edificios de gran envergadura. En cambio en las cabeceras se procuró hacer construcciones, si no magníficas en grado extremo, sí que pusieron de manifiesto la importancia política, económica y eclesiástica del lugar; díganlo si no, la capilla de Tlaxcala, la de Tizatlán o la de Coyoacán; lo cual, por otra parte, no implica que dichos edificios sean perfectos en su estructura y realización. Sin embargo, no es esto lo que trato de discutir por ahora.

¿Qué razones hubo para cerrar dichas capillas? Resultaría poco acertado tratar de dar una respuesta definitiva a esta pregunta. Particularmente creo que cada caso de los aquí estudiados merece especial atención. No obstante, me atrevo a pensar que las capillas localizadas en el Distrito Federal empezaron a trasformarse durante el siglo xvil cuando la población disminuyó, por una parte, y por otra su cercanía con los grandes conjuntos conventuales como Coyoacán y San Ángel, no ameritaban construir nuevas fábricas que, dicho sea de paso, significaban cargas onerosas para los habitantes de aquellos barrios. No estará fuera de lugar recordar aquí las dificultades que tuvieron los dominicos de San Jacinto al tratar de construir su convento tan próximo al colegio carmelita de San Ángel. Considerando este caso no me parece aventurado afirmar que no era posible pensar en una construcción como Chimalistac, que al fin y al cabo era una población más ínfima que San Ángel, cuando los problemas fundamentales de la evangelización estaban totalmente liquidados. En todo caso el partido a tomar - por lo que se refiere al edificio en sí- era muy distinto; prueba de ello sería la cercana capilla de San Antonio Panzacola, que está concebida definitavamente dentro de un nuevo espíritu formal.

En Anenecuilco y Temimilcingo parece ocurrir un tanto lo contrario; por los vestigios de ambos edificios puede entreverse que las necesidades eclesiásticas aumentaron ligeramente durante los inicios 
del siglo xvir. Hecho que - posiblemente- llevó a los frailes encargados de administrar dichas visitas a ver la necesidad de construir conjuntos mayores. Sin embargo, los propios recursos económicos de esos pueblos no debieron ser tantos, pues aunque en Temimilcingo se logra terminar el monasterio, su factura resulta tosca en comparación con otras de la misma región. Parecido es el caso de Anenecuilco, pues hoy en día apenas si se advierte una parte del conjunto y no es fácil afirmar que haya llegado a total término.

De todas maneras es claro que poco tiempo después hubo un descenso en la economía de esos pueblos, pues no se construyen nuevas las iglesias, sino que se prefiere adaptar las antiguas capillas; adaptación que incluye el cambio de orientación de la iglesia, por ejemplo, el caso de Anenecuilco. La crisis económica debió continuar durante el siglo siguiente $y$, naturalmente, no hace falta mencionar lo que se refiere a la centuria pasada y lo que va de la actual.

Por todo lo anterior puede advertirse que la creación y construcción de este tipo de estructura, que llamamos capillas abiertas, se lleva a cabo exclusivamente durante el siglo xvi. Con el tiempo y por diversas razones esos edificios se adaptan a las nuevas necesidades de culto; es decir, pierden totalmente el sentido para el cual fueron construidas originalmente.

Aunque es demasiado tentativo pienso que dichas trasformaciones, en planta y alzado, fueron hechas en tiempos novohispanos; exceptuando los casos del Distrito Federal que dada su cercanía con la capital han sido objeto de remodelaciones recientes que, en alguna medida, los han privado de su encanto "colonial". 